\title{
PREMOLAR INFERIOR CON DOS CONDUCTOS
}

Monique Marie Gay Ortiz, Odontóloga Universidad Javeriana,

Residente II Año Posgrado de Endodoncia, U. Santo Tomás.

Autor responsable de correspondencia: Monique Marie Gay 0.

e-mail:mmtgo@hotmail.com

\begin{abstract}
RESUMEN
La anatomía interna de los primeros premolares inferiores es variable, lo que dificulta una adecuada limpieza y conformación. El objetivo de este artículo es reportar el caso de un premolar inferior con dos conductos. [Gay MM. Premolar inferior con dos conductos: reporte de un caso. Ustasalud 2003;1:51-53].
\end{abstract}

PALABRAS CLAVES: Primer premolar inferior, Anatomía interna, Conducto radicular.

Mandibular First Premolar With Two Canals

\begin{abstract}
The internal anatomy of mandibular first premolars is variable. Therefore, it makes difficult to a suitable cleaning and conformation. The objective of this article is to report a case of premolar inferior with two canals.
\end{abstract}

KEY WORDS: Mandibular first premolar, Internal anatomy, Root canal system.

Recibido para publicación: marzo 4 de 2003, Aceptado para publicación: mayo 5 de 2003

\section{INTRODUCCIÓN}

Desde los estudios de Hess y Zurcher,, hasta los más recientes, se muestra la complejidad anatómica del sistema de conductos radicular. Lo que se consideraba normal para los premolares, es decir, una raíz con un conducto estrecho y un foramen único, parecen ser casos aislados, pues se ha demostrado que la mayoría de ellos, presentan múltiples forámenes, deltas apicales, curvaturas, conductos accesorios y un sin número de variaciones anatómicas. ${ }^{3,4}$

Tal vez, uno de los dientes que presenta el mayor número de variaciones anatómicas es el primer premolar inferior; que erupciona entre los 10 y 12 años, finaliza su formación radicular hacia los 12 ó 13 años y tiene una longitud radicular promedio de $21.6 \mathrm{~mm}$., algunas veces no presenta un conducto individual, sino en cinta. ${ }^{3}$

La corona de este diente tiene una cúspide vestibular bien desarrollada, al contrario, de la lingual, que es pequeña 0 , en muchos casos, inexistente. La cámara pulpar generalmente es redonda, si hay un solo conducto, y ovoide en los dientes con dos conductos. ${ }^{3}$
En el $75 \%$ de los casos presenta un conducto único; el $25 \%$ restante tiene dos conductos; éstos pueden subdividirse en cualquier nivel de la raíz, generando problemas en la limpieza y conformación. ${ }^{4}$ Zillich R y Downson, en 1973, informaron la existencia de un segundo o tercer conducto, en por lo menos, el $23 \%$ de los primeros premolares inferiores. ${ }^{5}$

Por otra parte, Baisden y col. observaron que el $14 \%$ de los raíces de los premolares inferiores con un solo conducto y dos forámenes presentaban un conducto en C. ${ }^{6}$

\section{REPORTE DE UN CASO}

Paciente de género masculino, 25 años de edad, que llegó la Clínica Odontológica de Pregrado de la Universidad Santo Tomás, en Floridablanca para un tratamiento de operatoria. al ser identificada su complejidad, fue remitido a la Clínica del Posgrado de Endodoncia; El examen físico no mostró ningún antecedente médico de importancia. 
En el examen intraoral se observó caries extensa con destrucción coronal en el 44; expuesto al medio ambiente oral, las pruebas de sensibilidad pulpar eran negativas, las pruebas periapicales eran positivas a la percusión y negativas a la palpación; no había presencia de inflamación ni de fistulas.

Radiográficamente, se observó caries oclusal profunda, se observaba luz de conducto hasta la unión del tercio medio y cervical, de tercio medio a apical la imagen radio lúcida del conducto desaparecía. Línea radio lúcida en el tercio apical compatible con bifurcación, ensanchamiento del ligamento periodontal lateral y zona radiolúcida de $0.5 \mathrm{~mm}$ asociada con la raíz vestibular. (Figura 1)

El diagnóstico: Periodontitis Apical Crónica No

Supurativa de etiología bacteriana; se inició el tratamiento endodóntico con técnica Crown Down, previo aislamiento con tela de caucho. Posteriormente, se continuó con la técnica Step- Back, con limas K - Flex y Limas $\mathrm{Ni}$ Ti; se irrigó con $\mathrm{NaOCl}$ al 5.25\%. Se tomó la radiografía de la conductometría con una lima 0.10 a $19 \mathrm{~mm}$ en el conducto vestibular y $17 \mathrm{~mm}$ en el conducto lingual; el diente fue sellado con un cemento temporal Coltosol, para continuar en una segunda cita.

El paciente regresó a la consulta una semana después del procedimiento y reportó dolor moderado y leve molestia a la per-

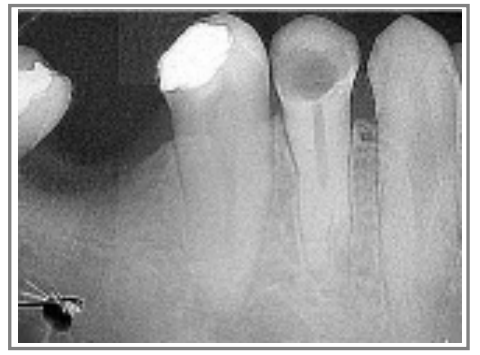

Figura 1.

Radiografia Inicial 44.

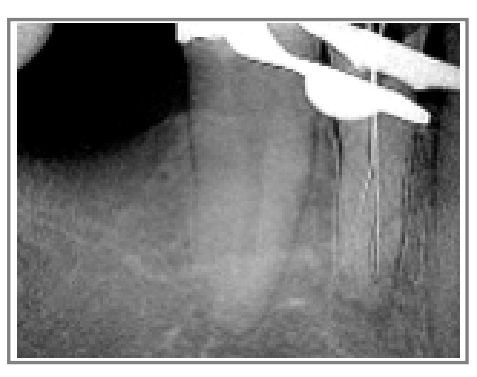

Figura 2.

Radiografía conductometría 44.

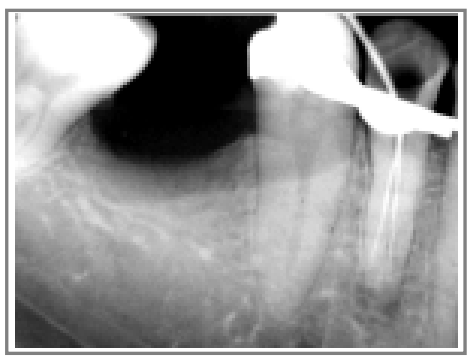

Figura 3. Radiografia conometría 44. cusión. Se anestesió, se realizó aislamiento con tela de caucho y la obturación temporal fue removida. El conducto fue irrigado con $\mathrm{NaOCl}$ al 5.25\%. Se verificó la longitud de trabajo, se intentó ganar longitud utilizando Rc Prep y una vez alcanzada la longitud máxima de 20 mm LAP 30 para el conducto vestibular y 19.5 LAP 25 para el conducto lingual, (Figura 2) se realizó la última irrigación con hipoclorito de sodio al $5.25 \%$. Se secó el conducto con puntas de papel, se procedió a la obturación con conos de gutapercha (Figura 3) y cemento Root Canal Sealer ${ }^{\circledR}$ (Sultan) con la técnica de condensación lateral y vertical (Figura 4). Se colocó gutapercha blanca a la entrada del conducto además de la obturación temporal con Coltosol (Figura 5).

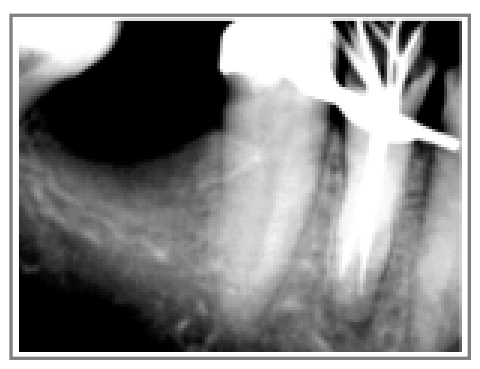

Figura 4 Radiografia obturación 44.

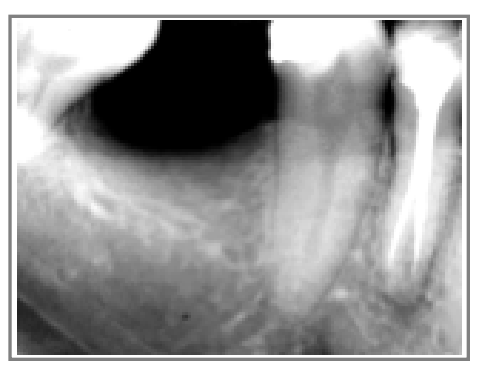

Figura 5 Radiografia final - Junio 14, 2002.

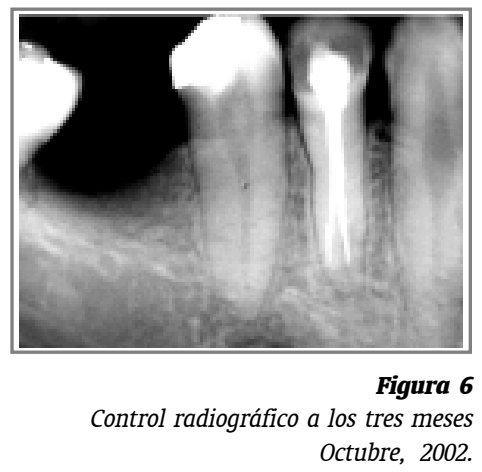

Tres meses después, se realizó un primer control. Clínicamente, el paciente continúa con la obturación temporal. Radiográficamente, se aprecia desaparición de la zona radiolúcida perirradicular. Sin embargo, el ensanchamiento del ligamento periodontal persiste. El paciente es citado para un segundo control en 3 meses (Figura 6).

\section{DISCUSIÓN}

Los estudios que describen la complejidad anatómica del sistema de conductos radicular, han demostrado que uno de lo dientes que presenta el mayor número de variaciones anatómicas es el primer premolar inferior. ${ }^{1-2}$ 
La etiología exacta de las anomalías radiculares sigue siendo incierta, aunque se ha podido establecer que las raíces adicionales están frecuentemente relacionadas con dientes que experimentan el desarrollo radicular después del nacimiento. Además existen algunos factores asociados como el trauma, la presión o las enfermedades metabólicas. ${ }^{7}$

El desarrollo radicular comienza una vez completada la formación del esmalte. Las células del epitelio interno y externo del esmalte proliferan y forman la vaina epitelial radicular de Hertwig, que determina el tamaño y la morfología de la raíz o de las raíces del diente. ${ }^{8}$

Las células del epitelio interno del esmalte ejercen influencia sobre las células mesenquimales adyacentes y permiten su diferenciación en preodontoblastos y odontoblastos. Una vez mineralizada la primera capa de la matriz de dentina, aparecen espacios o gaps en la vaina radicular, permitiendo que las células mesenquimales del saco dental se muevan y entren en contacto con la dentina recién formada. Estas células se diferencian entonces en cementoblastos y depositan la matriz del cemento sobre raíz. ${ }^{8}$

En la formación de los dientes multiradiculares, el crecimiento epitelial juega un papel fundamental. A partir de la vaina radicular se prolongan extensiones epiteliales, posteriormente una porción de la raíz toma forma de tronco y los extremos horizontales libres de estas aletas epiteliales crecen hacia otros, se fusionan y de esta manera originan múltiples raíces. ${ }^{7}$

Vertucci encontró dos conductos en el $25.5 \%$ y tres conductos solo en el $0.5 \%$ de los primeros premolares inferiores. ${ }^{9-10}$

Hess reportó que la división del conducto radicular en los primeros premolares inferiores es del 2.3\% y en los segundos premolares inferiores del 7.6\%.1 Estas subdivisiones se pueden presentar en cualquier nivel de la raíz, generando problemas en la limpieza y conformación. ${ }^{3-4} \mathrm{Sin}$ embargo Sommer y colaboradores, indicaron que el conducto del primer premolar inferior tiende a bifurcarse en el tercio apical. ${ }^{7}$

El reporte de este caso, demuestra claramente las variaciones anatómicas que se pueden presentar en un primer premolar inferior. La radiografía inicial indicaba una configuración radicular anormal, se observaba luz de conducto hasta la unión del tercio medio y cervical, de tercio medio a apical la imagen radio lúcida del conducto desaparecía. Esto sugiere que la desaparición repentina de la imagen del conducto radicular en la radiografía corresponde a una bifurcación. ${ }^{7}$

La posibilidad de conductos adicionales de la raíz debe ser considerada en el examen clínico y radiográfico del paciente. ${ }^{11}$

La valoración radiográfica de las variaciones morfológicas de estos dientes es muy importante y aunque los resultados radiográficos no son del todo exactos, son clínicamente relevantes. Serman, ${ }^{12}$ realizó una investigación con 547 radiografías periapicales de premolares inferiores tomadas con técnica de paralelismo para determinar la incidencia de varias raíces y conductos en premolares inferiores. En 99 pacientes, el 18,1\% tenía por lo menos un premolar con dos conductos divididos o dos raíces, de este porcentaje el 15,7\% correspondían a los primeros premolares y el 7\% a los segundos premolares.

La clave para realizar un tratamiento en estos dientes, es la valoración radiográfica pre - operatoria que debe incluir radiografías con diferentes angulaciones ${ }^{7}$, además es importante realizar una adecuada apertura que permita el acceso y la visibilidad necesarias para lograr una apropiada limpieza y conformación de los conductos.

Realizar un diagnóstico incorrecto puede conducir a complicaciones inesperadas durante el tratamiento endodóntico e incluso a la exodoncia de estos dientes.

\section{BIBLIOGRAFÍA}

1. Hess W, Zuecher E. The anatomy of the root canals of the permanent and deciduous dentition. New York, William Wood y Co.1925

2. Pineda F, Kuttler Y. Mesiodistal and Bucolingual roentgenographic investigation of 7.275 roots canals. Oral Surg Oral Med Oral Pathol 1972; 33: 101.

3. Burns. R, Herbranson EJ. Morfología dental y cavitaria. En: Vías De La Pulpa. Séptima Edición. Madrid. Editorial Harcourt- Mosby 1999; 150 202.

4. Walton R. Vertucci F. Anatomía Interna. En: Endodoncia Principios y Práctica. Segunda Edición. México. McGraw-Hill Interamericana. 1996; 177191. 
5. Zillich R, Downson J. Root canal morphology of mandibular first and second premolars. J Oral Surgery 1973; 36: 738.

6. Baisden MD, Kulild JC, Weller RN. Root Canal configuration of the mandibular first premolar. J Endod 1992; 18: 505.

7. Prabhu, N.T. R. John \& A.K. Munshi Aberrant root development of the mandibular premolars: a case report International Journal of Paediatric Dentistry 1999; 9: 49

8. Trowbridge, H. Kim, S. Desarrollo de la Pullpa, estructura y Función En: Vías De La Pulpa. Séptima Edición. Madrid. Editorial HarcourtMosby 1999; 362- 400.

9. Vertucci FJ. Root canal morphology of mandibular premolars. J Am Dent Assoc 1978; 97: 47.

10. Vertucci FJ. Root canal anatomy of the human permanent teeth. Oral Surgery 1984: 58: 589 -599.

11. Hulsmann M. Mandibular first premolar with three root canals. Endod Dent Traumatol 1990;4:189 - 91

12. Serman NJ \& Hasselgren G. The radiographic incidence of multiple roots and canals in human mandibular premolars. International Endodontic Journal 1992; 25: 234 - 237. 